\title{
Diagnostic Criteria for Gastro-esophageal Reflux Following Sleeve Gastrectomy
}

\author{
Gillian Lim $^{1} \cdot$ Yazmin Johari ${ }^{1,2}$ (I) Geraldine Ooi ${ }^{1,2} \cdot$ Julie Playfair $^{1} \cdot$ Cheryl Laurie $^{1} \cdot$ Geoffrey Hebbard $^{3}$. \\ Wendy Brown ${ }^{1,2} \cdot$ Paul Burton ${ }^{1,2}$
}

Received: 25 July 2020 / Revised: 15 November 2020 / Accepted: 30 November 2020 / Published online: 25 January 2021

(C) The Author(s) 2021

\begin{abstract}
Background Gastro-esophageal reflux disease (GERD) post-sleeve gastrectomy (SG) is a controversial issue and diagnostic dilemma. Strong heterogeneity exists in the assessment of reflux post-SG, and better diagnostic tools are needed to characterize symptomatic reflux. We aimed to determine the discriminant factors of symptomatic reflux and establish diagnostic thresholds for GERD following SG.

Materials and Methods Patients post-SG were categorized into asymptomatic and symptomatic cohorts and completed validated symptom questionnaires. All patients underwent stationary esophageal manometry and 24-h ambulatory pH monitoring. Univariate and multivariate analyses were conducted to determine the strongest discriminant factors for GERD.

Results Baseline characteristics of the asymptomatic cohort $(n=48)$ and symptomatic cohort $(n=76)$ were comparable. The median post-operative duration was $7.3(14.1)$ vs $7.5(10.7)$ months $(p=0.825)$. The symptomatic cohort was more female predominant $(90.8$ vs $72.9 \%, p=0.008)$. Reflux scores were significantly higher in the symptomatic group (36.0 vs $10.5, p=$ 0.003 ). Stationary manometry parameters were similar, including hiatus hernia prevalence and impaired esophageal motility. The symptomatic cohort had significantly higher total acid exposure, especially while supine $(11.3 \% \mathrm{vs} 0.6 \%, p<0.001)$. Univariate and multivariate regressions delineated reflux score and supine acid exposure as discriminant factors for symptomatic reflux. The thresholds for distinguishing symptomatic reflux are as follows: reflux score of 11.5 (sensitivity $84.0 \%$, specificity $68.2 \%$ ) and supine acid exposure of $2.65 \%$ (sensitivity $67.1 \%$, specificity $70.8 \%$ ).

Conclusion A reflux score of 11.5 or more or supine acid exposure of $2.65 \%$ or more should be considered diagnostic in defining symptomatic reflux following SG.
\end{abstract}

Keywords Sleeve gastrectomy · Gastro-esophageal reflux disease $\cdot$ Diagnostic thresholds $\cdot$ High-resolution esophageal manometry $\cdot 24$-h ambulatory $\mathrm{pH}$ monitoring

\section{Introduction}

Gastro-esophageal reflux disease (GERD) post-sleeve gastrectomy (SG) is a significant issue. Severe symptoms, need

Yazmin Johari

yazmin.joharihalimshah@monash.edu

1 Department of Surgery, Central Clinical School, Monash University, Level 6, Alfred Centre, 99 Commercial Rd, Melbourne, VIC 3004, Australia

2 Oesophago-gastric and Bariatric Unit, Department of General Surgery, The Alfred Hospital, Melbourne, Australia

3 Department of Gastroenterology, Royal Melbourne Hospital and University of Melbourne, Melbourne, Australia for lifelong medical therapy or revisional surgery [1, 2], and development of Barrett's esophagus have been reported. Genco et al. and Sebastianelli et al. cited the prevalence of de novo Barrett's esophagus as $18.8 \%$ at 78 months and $17.2 \%$ at 145 months post-operative $[3,4]$. Given the altered anatomy and incompletely understood physiology of the procedure, it is critical that accurate and specific means of diagnosing pathological GERD are established.

In a 2011 systematic review by Chiu et al., only 4 studies out of 15 reported an increased propensity for reflux post-SG [5]. Systematic reviews in 2016 and 2020 reported an increase in reflux post-operatively, ranging from 19 to $20 \%$ with strong heterogeneity among studies on post-SG reflux symptoms [6, 7]. Assessment tools used included subjective symptom reporting and structured questionnaires. Despite the increase in 
reflux symptoms post-SG in many patients, satisfaction and quality of life were still acceptable and comparable to RYGB [8].

Several mechanisms are theorized to increase GERD following SG including altered lower esophageal sphincter (LES) basal tone [9], hiatus hernia [10], and decreased gastric compliance [11]. Accelerated gastric emptying [12] and sustained weight loss have been posited to produce the opposite effect. In the midst of this debate, however, a consensus framework on the etiology of GERD post-SG has not been established.

Previous studies using esophageal manometry and 24-h pH monitoring have demonstrated variable results but have not yet established diagnostic thresholds. Burgerhart et al. and Gorodner et al. reported increased acid exposure at $193 \%$ at 3 months and $102 \%$ at 12 months post-operative, respectively [13, 14]. Similarly, Braghetto et al. found persistent elevation of the DeMeester score in symptomatic patients at 5-9 years followup [9]. Conversely, Rebecchi et al. found improvement in total acid exposure and DeMeester score 2 years post-SG in patients with preoperative pathological $\mathrm{pH}$ profiles, with minimal change in LES basal pressure and esophageal contractility [15].

We hypothesized that the altered anatomy and physiology of SG would require unique, specific criteria to reliably diagnose GERD following SG. We therefore aimed to establish these criteria using esophageal manometry and 24-h pH monitoring.

\section{Methods}

\section{Patient Selection}

Ethics approval was obtained from the Alfred Human Research and Ethics Committee (HREC) no. 380/16 and the Avenue Hospital HREC no. 236. Patients who underwent SG from April 2014 to May 2019 were recruited for this prospective study, and informed written consent was obtained. Laparoscopic SG was performed as previously described [16]. Day 1 post-operative contrast swallow was performed for anatomical definition. All patients underwent a modified diet protocol with gradual transition from liquid to semi-solid diet as well as a proton pump inhibitor for 6 weeks post-operative. Normal diet was instituted after 6 weeks with cessation of the proton pump inhibitor if not clinically required.

- Inclusion criteria: age between 18 and 65 years, at least 6 weeks post-operative with a confirmed anatomically unremarkable sleeved stomach on contrast swallow. This was defined as a tubular-shaped sleeved stomach with no retained stomach and good flow of contrast without anatomical obstruction or leak.

- Exclusion criteria: previous non-bariatric esophago-gastric surgery, pre-existing esophago-gastric motility disorder, and known pre-operative or intra-operative medium to large hiatus hernia.
Participants were categorized based on Visick scoring [17] into asymptomatic (Visick scores I and II) and symptomatic (Visick scores III and IV).

\section{Data Collection and Outcome Measures}

Baseline and post-operative anthropometric data were collected at routine follow-up. Total body weight loss percentage (TBWL\%) was defined as percentage of weight loss compared to pre-operative weight. Excess weight loss percentage (EWL\%) was calculated as weight loss from pre-operative excess weight compared to ideal weight at BMI 25.

Participants also completed validated symptom questionnaires for reflux [18] and dysphagia [19].

\section{Stationary Manometry}

A 16-channel silicone nasogastric manometry catheter with a water-perfused system (Mui Scientific, Ontario, Canada) was used with real-time recording facilitated by TRACE!1.2 (written by G Hebbard using LabVIEW, National Instruments, Austin, TX). Participants ceased proton pump inhibitor or $\mathrm{H} 2$ antagonist use 10 days prior and were permitted to have a light breakfast and clear fluids the morning of the investigation. A standardized protocol [20] was utilized, consisting of $60 \mathrm{~s}$ of supine basal recording, five deep inspirations, ten wet swallows each with $5 \mathrm{ml}$ of water, and five consecutive swallows of $10 \mathrm{ml}$ of water in rapid succession.

A reference point was drawn from the basal end-expiratory intragastric pressure. Impaired esophageal motility, LES basal pressure, and hiatus hernias were recorded (Fig. 1). Esophageal motility was analyzed according to a published guideline [21]. LES basal pressure was defined as peak end-expiratory LES pressure and LES relaxation percentage as basal pressure at the initiation of swallowing. The crural diaphragm was identified at the axial level of maximal inspiratory pressure. Hiatus hernias were defined as axial separation of the LES and the diaphragm.

\section{Ambulatory 24-H pH Monitoring}

The $\mathrm{pH}$ catheter (Innologic, Australia) was inserted via nasogastric intubation and positioned $5 \mathrm{~cm}$ above the LES, which was visualized during manometry. Across $24 \mathrm{~h}$, participants were instructed to consume a normal diet, bar acidic foods. Participants kept a diary of symptoms, food intake, and significant change of posture.

Fig. 1 Stationary manometry variables: comparison of basal manometry and manometric trace of a swallow. (a) Normal LES basal tone. (b) Hypotensive LES basal tone. (c) Hiatus hernia (white arrow representing a pocket of high pressure in the hiatus hernia). (d) Impaired/uncoordinated esophageal peristalsis 


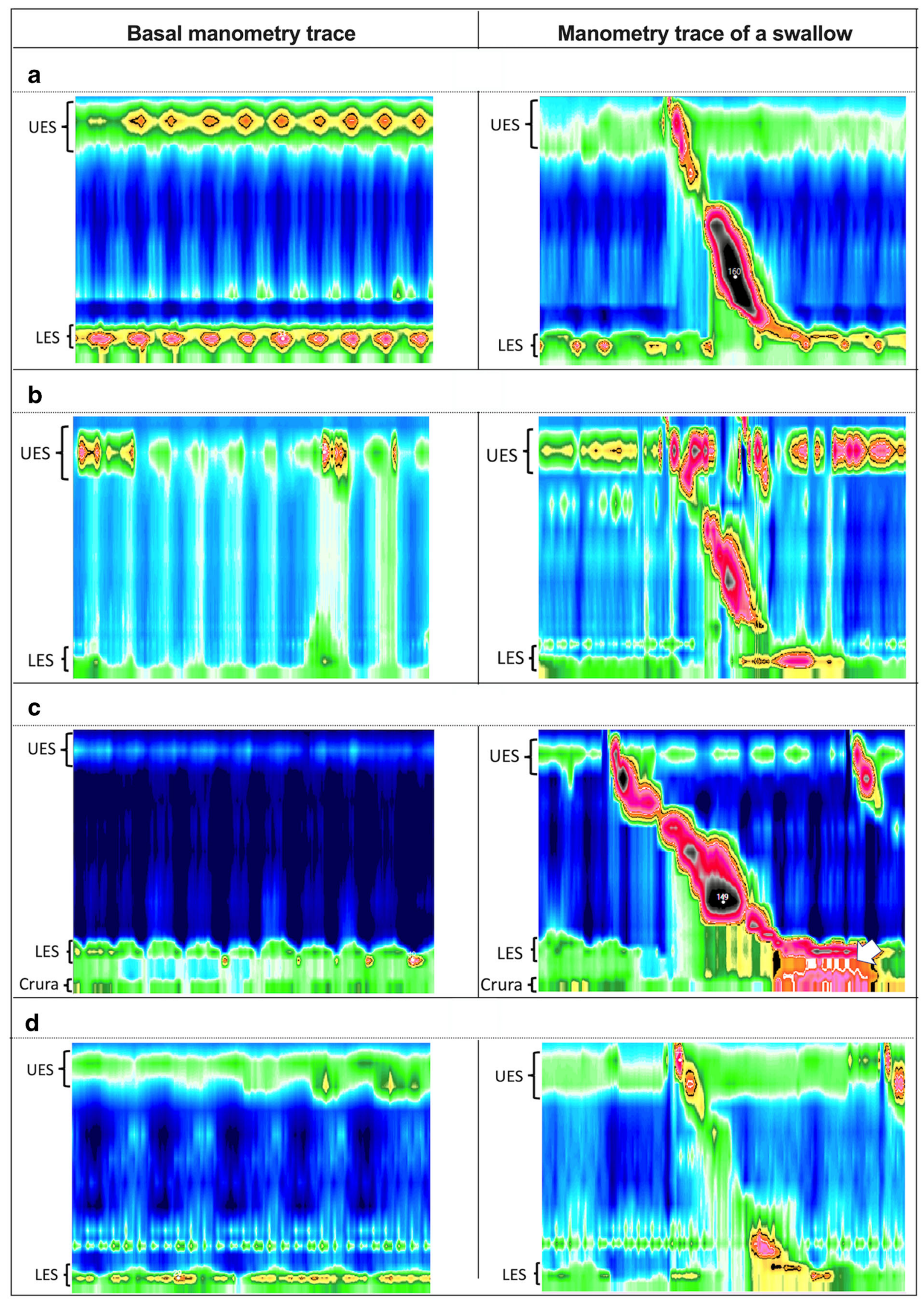


The 24-h $\mathrm{pH}$ data was analyzed using Vanilla $\mathrm{pH} 1.1$ (written by G Hebbard using LabVIEW, National Instruments, Austin, TX). Reflux events were defined as episodes of esophageal $\mathrm{pH}$ less than four for 5 or more seconds. Variables collected were the acid exposure, number of events, and duration of acid events. Reflux patterns (Fig. 2) were defined by inspection of 24-h $\mathrm{pH}$ traces:
- Minimal reflux - Total acid exposure less than 3\% and minimal reflux events

- Irritant reflux - Total acid exposure more than 3\% with numerous short reflux events (average duration of each acid events of less than $1 \mathrm{~min}$ )

- Volume reflux -Total acid exposure more than 3\% with long reflux events (average duration of each acid events of more than $1 \mathrm{~min}$ )

a Minimal reflux

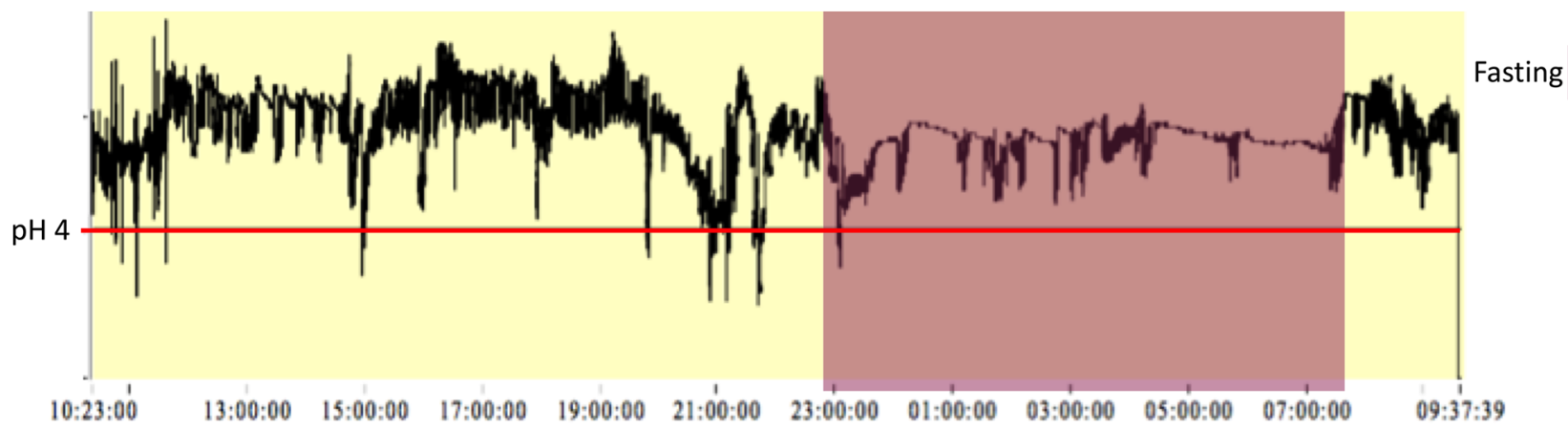

Time

b Irritant reflux

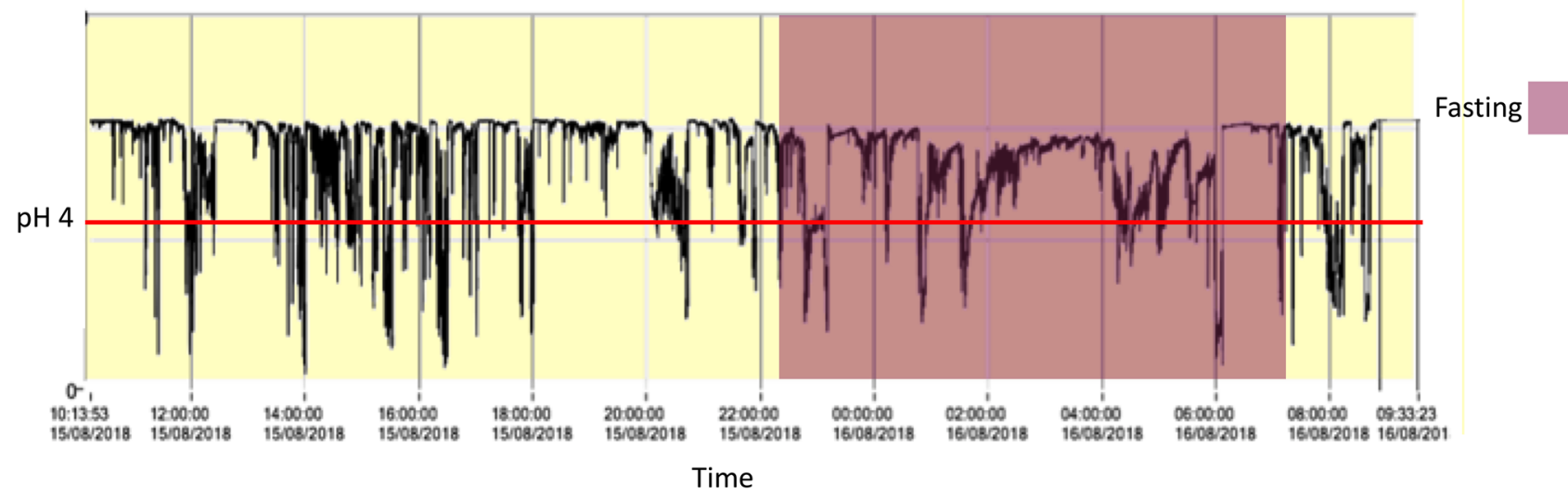

C Volume reflux

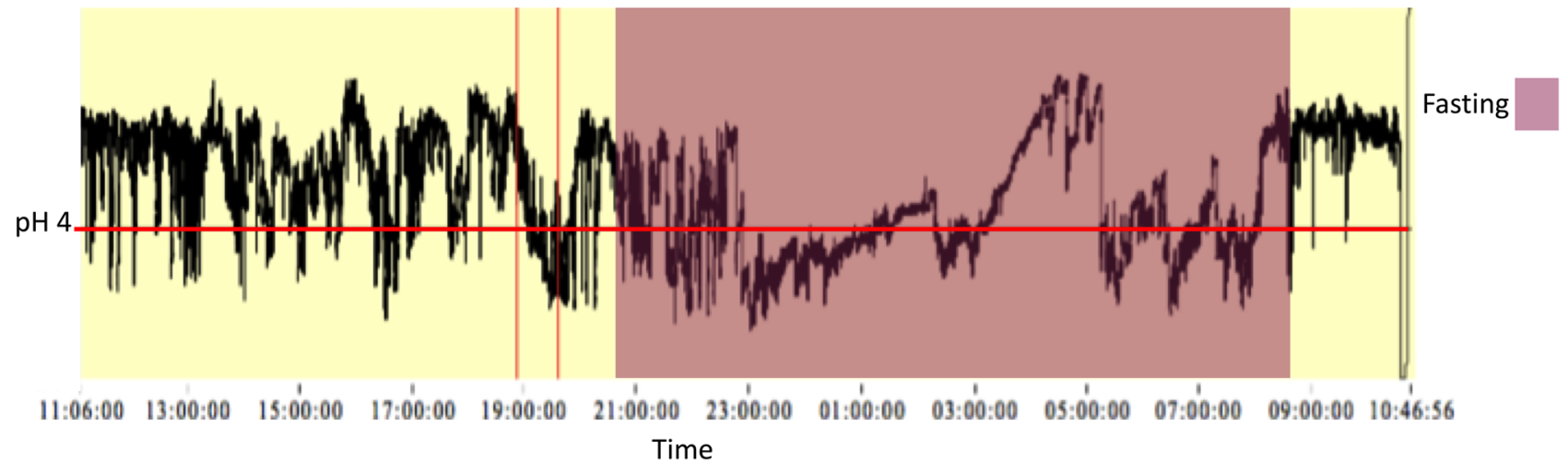

Fig. 2 Patterns of reflux on 24-h ambulatory $\mathrm{pH}$ monitoring. (a) Minimal reflux - minimal acid exposure and reflux events. (b) Irritant refluxmultiple reflux events with short duration of acid exposure in both supine

and erect states. (c) Volume reflux-longer duration of reflux events during the supine state 


\section{Candidate Variables}

Variables considered likely for the diagnosis of GERD postSG are listed in Table 1. We performed further analysis on clinical, manometric, and $\mathrm{pH}$ variables that correlated with the presence of hiatus hernia post-SG.

\section{Data Representation and Statistical Analysis}

Univariate binary logistic regression was used to determine the relationship between each variable and the cohorts (asymptomatic valued as 0 and symptomatic as 1 ). Multivariate binary logistic regression with stepwise backward (Wald) was used to determine the relationship between statistically significant variables in the univariate analysis and cohorts. Omnibus tests of model coefficients were used to determine overall model fit and statistical significance. Nagelkerke $R^{2}$ method was used to determine how much variation can be explained by the model. The receiver operating characteristic (ROC) curves were created using significant variables from the multivariate regression to determine thresholds that discriminate symptomatic reflux. The area under the curve (AUC) was classified according to Hosmer et al., where AUC more than 0.9 was considered outstanding, between 0.8 and 0.9 excellent, between 0.7 and 0.8 acceptable, and less than 0.7 poor discrimination [22].

Data was compiled using a customized Microsoft Access 2010 database (Microsoft Corporation, Redmond, WA, USA) connected to SQL server. Statistical analysis was performed using SPSS version 26 (SPSS Inc., Chicago, IL, USA) and GraphPad Prism version 8.3.0 (GraphPad Software, San Diego, CA, USA).

\section{Results}

\section{Cohort Characteristics}

A total of 124 participants were included: 48 asymptomatic and 76 symptomatic. The demographic data is displayed in Table 2 . Cohorts were mostly demographically similar; however, there was a higher proportion of female participants in the symptomatic cohort. Weight loss was significant and similar between cohorts at median follow-up of 7.4 months. The reflux score was expectedly higher for the symptomatic cohort, but the dysphagia score did not vary significantly between cohorts.

Stationary manometry revealed similar LES relaxation percentage, LES basal tone, and impaired esophageal peristalsis incidence. The prevalence of hiatus hernias (Fig. 1c) was comparable. There was no hiatus hernia larger than $5 \mathrm{~cm}$ in either cohort.

Ambulatory 24-h pH monitoring displayed a markedly high acid exposure profile among symptomatic participants. Erect acid exposure was elevated in the symptomatic cohort, as was supine acid exposure. Symptomatic patients were more likely to demonstrate a volume reflux pattern.

\section{Univariate and Multivariate Analyses of Distinguishing Factors of Symptomatic Reflux}

Table 3 shows the univariate and multivariate binary regression analyses to identify factors delineating symptomatic reflux. From the univariate analysis, gender (OR 3.661), reflux score (OR 1.031), and several 24-h pH variables (OR ranged from 1.017 to 1.221 ) were significant. Stationary manometry variables did not reach statistical significance in the univariate analysis and were excluded from the multivariate analysis.

The binary regression model was statistically significant (chi-square 28.553, $p<0.001$ ). The model explained 60.8\% (Nagelkerke $R^{2}$ ) of the variance in reflux symptom severity following SG. Only three variables correlated positively and significantly with symptomatic reflux. The reflux score produced OR $1.033(p=0.038)$, and the discriminant ability of the ROC curve (Fig. 3a) score was acceptable (AUC $=0.751$, $p=0.003$ ). A threshold of 11.5 distinguished symptomatic reflux with $84.0 \%$ sensitivity and $68.2 \%$ specificity.

From 24-h pH monitoring, higher supine acid exposure was associated with an increased likelihood of symptomatic reflux (OR 1.224, $p=0.010$ ). The discriminant ability of the ROC curve (Fig. 3b) was also acceptable (AUC $=0.741, p<0.001$ ). A threshold of $2.65 \%$ discriminated symptomatic reflux with
Table 1 Candidate variables for the diagnosis of GERD

\begin{tabular}{lll}
\hline Demographic and clinical parameters & 24-h pH monitoring parameters & Manometric parameters \\
\hline Age & Total esophageal acid exposure & LES basal tone \\
Gender & Total number of reflux events & LES relaxation percentage \\
Preoperative weight and BMI & Mean duration of reflux events & Impaired esophageal peristalsis \\
EWL\% & Erect esophageal acid exposure & Hiatus hernia \\
Revisional SG & Supine esophageal acid exposure & \\
Duration from surgery & Supine reflux event percentage & \\
Reflux score & Reflux patterns & \\
Dysphagia score & & \\
\hline
\end{tabular}


Table 2 Characteristics of the asymptomatic and symptomatic cohorts

\begin{tabular}{|c|c|c|c|}
\hline & Asymptomatic & Symptomatic & $p$ value \\
\hline$N$ & 48 & 76 & \\
\hline Age, years & $47.6 \pm 11.6$ & $44.1 \pm 11.4$ & $0.103 *$ \\
\hline Female gender, $N(\%)$ & $35(72.9)$ & $69(90.8)$ & $0.008^{\#}$ \\
\hline Pre-operative weight, $\mathrm{kg}$ & $133.4 \pm 25.2$ & $126.5 \pm 23.8$ & $0.129 *$ \\
\hline Pre-operative BMI, $\mathrm{kg} / \mathrm{m}^{2}$ & $47.5 \pm 7.2$ & $45.6 \pm 8.0$ & $0.188 *$ \\
\hline Total body weight loss, $\%$ & $29.2 \pm 17.6$ & $31.6 \pm 16.7$ & $0.455^{*}$ \\
\hline Excess weight loss, $\%$ & $53.2 \pm 27.4$ & $55.5 \pm 25.4$ & $0.650 *$ \\
\hline Revisional sleeve gastrectomy, $N(\%)$ & $8(16.7)$ & $16(21.6)$ & $0.501^{\#}$ \\
\hline Duration from surgery, median (IQR), months & $7.3(14.1)$ & $7.5(10.7)$ & $0.825^{\wedge}$ \\
\hline \multicolumn{4}{|l|}{ Adverse gastrointestinal symptoms, median (IQR) } \\
\hline Reflux & $10.5(21.5)$ & $36.0(26.8)$ & $0.003^{\wedge}$ \\
\hline $\begin{array}{l}0=\text { no reflux to } 72=\text { frequent reflux } \\
\text { Dysphagia }\end{array}$ & $7.3(16.5)$ & $12.3(17.3)$ & $0.125^{\wedge}$ \\
\hline \multicolumn{4}{|l|}{$\begin{array}{l}0=\text { no dysphagia to } 45=\text { frequent dysphagia } \\
\text { Stationary manometry }\end{array}$} \\
\hline LES relaxation, median (IQR), \% & $76.4(24.2)$ & $68.5(47.7)$ & 0.224 \\
\hline LES basal tone, median (IQR), $\mathrm{mmHg}$ & $17.1(15.8)$ & $12.9(16.0)$ & 0.112 \\
\hline Axial separation of LES and diaphragm (hiatus hernia), $N(\%)$ & $16(33.3)$ & $30(39.5)$ & 0.566 \\
\hline Size of hiatus hernia, median (IQR), $\mathrm{cm}$ & $3.0(1.4)$ & $3.5(1.3)$ & 0.217 \\
\hline Impaired esophageal peristalsis, $N(\%)$ & $11(22.9)$ & $28(36.8)$ & 0.085 \\
\hline \multicolumn{4}{|l|}{ 24-h pH monitoring } \\
\hline Total acid exposure, median (IQR), \% & $4.0(5.2)$ & $9.2(13.0)$ & $<0.001^{\wedge}$ \\
\hline Number of acid events, median (IQR), $N$ & $37(37)$ & $50(54)$ & $<0.001^{\wedge}$ \\
\hline Duration of each acid event, median (IQR), minutes & $1.2(2.6)$ & $2.3(2.5)$ & $0.435^{\wedge}$ \\
\hline Erect acid exposure, median (IQR), \% & $5.0(7.7)$ & $7.6(9.1)$ & $<0.001^{\wedge}$ \\
\hline Supine acid exposure, median (IQR), \% & $0.6(7.0)$ & $11.3(17.6)$ & $<0.001^{\wedge}$ \\
\hline Supine reflux event percentage, median (IQR), \% & $10.0(18.6)$ & $22.8(21.4)$ & $0.005^{\wedge}$ \\
\hline Reflux patterns & & & $0.001^{\beta}$ \\
\hline Minimal reflux, $N(\%)$ & $23(47.9)$ & $14(18.4)$ & $<0.05$ \\
\hline Irritant reflux, $N(\%)$ & $11(22.9)$ & $18(23.7)$ & $>0.05$ \\
\hline Volume reflux, $N(\%)$ & $14(29.2)$ & $44(57.9)$ & $<0.05$ \\
\hline
\end{tabular}

*Student's $t$ test

${ }^{\#}$ Chi-square

${ }^{\wedge}$ Mann-Whitney

${ }^{\beta}$ Fisher's exact test with column proportion comparisons (Bonferroni method)
$67.1 \%$ sensitivity and $70.8 \%$ specificity. Supine reflux acid exposure event percentage correlated positively with symptomatic reflux, with OR $1.072(p=0.038)$. However, this variable was a poor discriminator of symptomatic reflux $(\mathrm{AUC}=0.649, p=$ 0.006 ) (Fig. 3c). A threshold of $11.7 \%$ distinguished symptomatic reflux with $73.0 \%$ sensitivity and $51.2 \%$ specificity (Fig. 4).

\section{Subgroup Analysis: Factors Associated with the Presence of Hiatus Hernia}

Univariate analysis (Table 4) showed that several $\mathrm{pH}$ variables have significant positive correlation with hiatus hernias: supine acid exposure (OR 1.043, $p=0.018)$ and volume reflux pattern (OR 2.132, $p=0.047$ ). Hiatus hernias were negatively correlated with minimal reflux pattern (OR 0.301, $p=0.012$ ). The association between hiatus hernias and symptomatic reflux was not statistically significant (OR 1.250, $p=0.566$ ).

A stepwise backward multivariate model revealed significant positive correlation between supine acid exposure and hiatus hernia (OR 1.049, 95\% CI 1.010-1.090, $p=0.013$ ). The model lacked generality (Nagelkerke $R^{2}$ 0.082 ) despite being a statistically significant model (chi-square 7.227, $p=0.007$ ). 
Table 3 Univariate and multivariate binary logistic regressions of factors associated with symptomatic reflux

\begin{tabular}{|c|c|c|c|c|c|c|}
\hline \multirow[t]{2}{*}{ Variable } & \multicolumn{3}{|c|}{ Univariate regression } & \multicolumn{3}{|c|}{ Stepwise multiple regression* } \\
\hline & Odds ratio & $95 \%$ confidence interval & $p$ value & Odds ratio & $95 \%$ confidence interval & $p$ value \\
\hline Age & 0.974 & $0.943-1.005$ & 0.105 & & & \\
\hline Gender & 3.661 & $1.340-10.001$ & 0.011 & & & \\
\hline Pre-operative weight & 0.988 & $0.974-1.003$ & 0.130 & & & \\
\hline Pre-operative BMI & 0.969 & $0.923-1.016$ & 0.189 & & & \\
\hline Excess weight loss & 1.003 & $0.989-1.017$ & 0.647 & & & \\
\hline Revisional sleeve gastrectomy & 1.379 & $0.539-3.529$ & 0.502 & & & \\
\hline Reflux score & 1.031 & $1.001-1.061$ & 0.040 & 1.033 & $1.002-1.065$ & 0.038 \\
\hline Dysphagia score & 1.050 & $0.987-1.116$ & 0.123 & & & \\
\hline Duration of follow-up & 0.995 & $0.976-1.014$ & 0.590 & & & \\
\hline LES relaxation \% & 0.989 & $0.975-1.002$ & 0.107 & & & \\
\hline LES basal tone & 0.987 & $0.961-1.013$ & 0.310 & & & \\
\hline Hiatus hernia & 1.250 & $0.583-2.680$ & 0.566 & & & \\
\hline Impaired esophageal peristalsis & 2.061 & $0.897-4.731$ & 0.088 & & & \\
\hline Total acid exposure & 1.221 & $1.107-1.347$ & $<0.001$ & & & \\
\hline Duration of each acid events & 1.132 & $0.889-1.442$ & 0.314 & & & \\
\hline Number of acid events & 1.017 & $1.007-1.026$ & 0.001 & & & \\
\hline Erect acid exposure & 1.165 & $1.062-1.279$ & 0.001 & & & \\
\hline Supine acid exposure & 1.168 & $1.071-1.273$ & $<0.001$ & 1.224 & $1.049-1.428$ & 0.010 \\
\hline Supine reflux event percentage & 1.023 & $1.003-1.043$ & 0.021 & 1.072 & $1.002-1.065$ & 0.038 \\
\hline Minimal reflux pattern & 0.245 & $0.109-0.552$ & 0.001 & & & \\
\hline Irritant reflux pattern & 1.044 & $0.444-2.457$ & 0.922 & & & \\
\hline Volume reflux pattern & 3.339 & $1.544-7.221$ & 0.002 & & & \\
\hline
\end{tabular}

*Stepwise Backward (Wald) multiple regression performed with gender, total acid exposure, number of acid events, erect acid exposure, supine acid exposure, supine reflux event percentage, reflux score, minimal and volume reflux pattern

Italics refers to statistically significant variables

\section{A Summary of Our Findings Is Listed in Box 1}

Box 1 Practical application for the diagnosis of GERD following sleeve gastrectomy

Objective diagnostic criteria of symptomatic reflux:

24-h ambulatory $\mathrm{pH}$ : Supine acid exposure more than $2.65 \%$

Reflux score (18) more than 11.5 out of 72

Important considerations:

Clinical

- Reflux scores are generally low-post-SG: the median reflux score of asymptomatic patients was 10.5 (IQR 21.5) out of 72

24-h ambulatory $\mathrm{pH}$ monitoring

- Higher acid exposure is expected post-SG: the median total acid exposure of asymptomatic patients was $4.0 \%$ (IQR 5.2)

Manometry

- Hiatus hernias, LES incompetence, and impaired peristalsis may play a role in the severity of reflux following SG

- No strong correlation between hiatus hernias and symptomatic reflux was found on subgroup analysis. However, hiatus hernias were associated with higher supine acid exposure

\section{Discussion}

We have identified two significant factors that can be reliably used to diagnose symptomatic reflux post-SG. These differ markedly from established criteria used to diagnose GERD in patients with an anatomically normal stomach. We demonstrated that a moderate increase in esophageal acid exposure is expected following SG. Despite the presence of elevated esophageal acid exposure, many patients did not experience significant reflux symptoms. Using defined normal values, we were able to identify a threshold supine acid exposure value for abnormal esophageal acid levels. Additionally, we identified a cut-off value that defined abnormal GERD post-SG using an established reflux score [18].

Our findings are in line with aspects of previous literature that have focused on discriminating symptomatic reflux. Reflux symptoms and abnormal 24-h $\mathrm{pH}$ score have been previously identified as significant factors in the identification of symptomatic reflux following laparoscopic fundoplication and were subsequently found to be strong predictors of success [23]. 


\section{a Reflux score ROC}
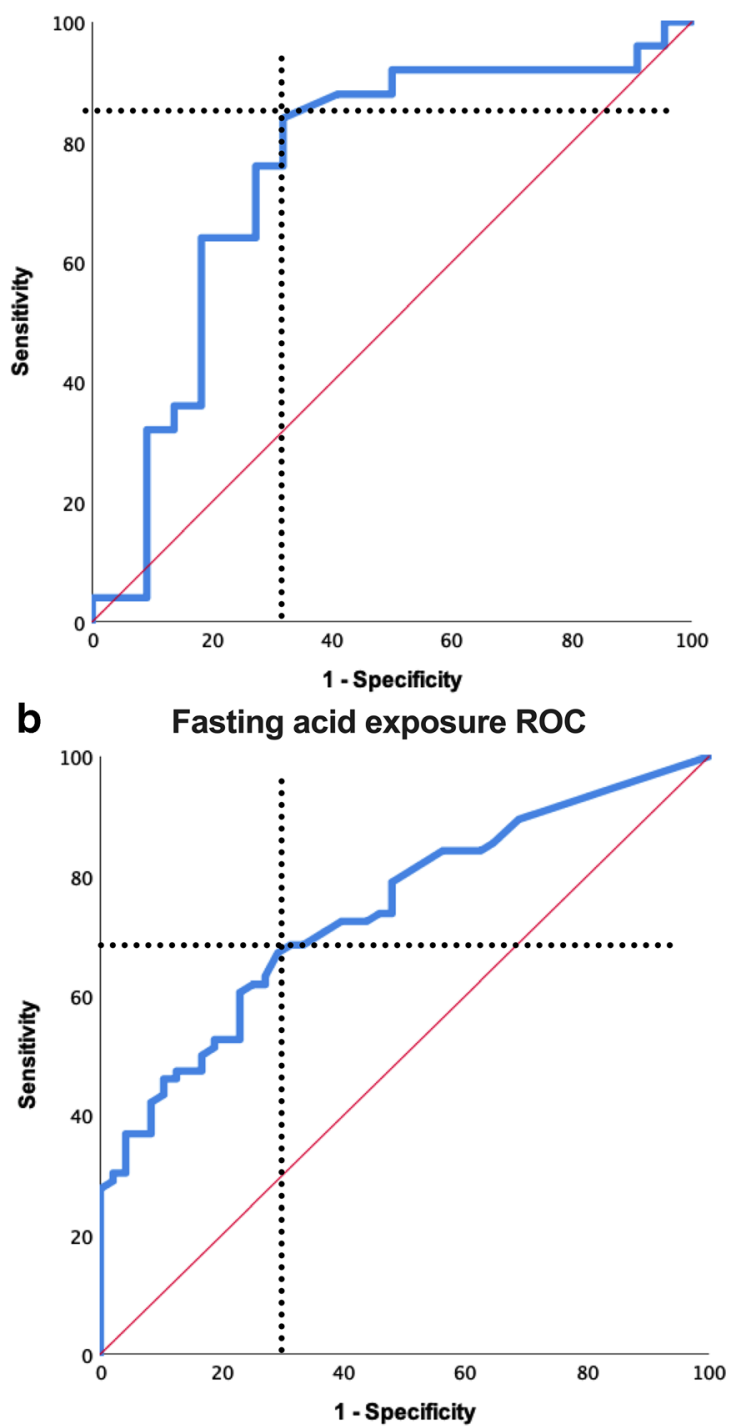

C Fasting reflux event percentage ROC

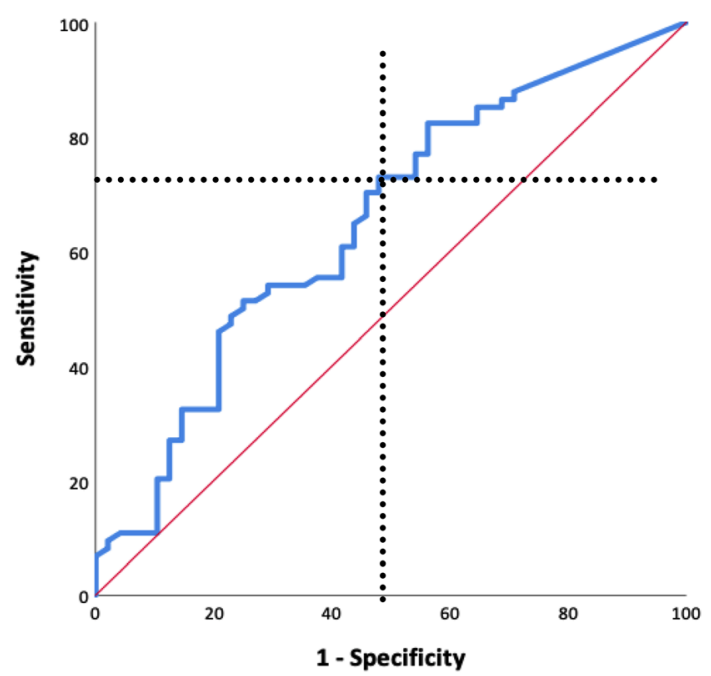

AUC $=0.751(95 \%$ confidence interval $0.601-0.901)$ $p=0.003$

For sensitivity $84.0 \%$ and specificity $68.2 \%$ (dotted line intersection), the threshold set at a reflux score of 11.5
AUC $=0.741$ (95\% confidence interval $0.656-0.827)$ $p<0.001$

For sensitivity $67.1 \%$ and specificity $70.8 \%$ (dotted line intersection), the threshold set at fasting acid exposure of $2.65 \%$

AUC $=0.649(95 \%$ confidence interval $0.549-0.750)$ $p=0.006$

For sensitivity $73.0 \%$ and specificity $52.1 \%$ (dotted line intersection), the threshold set at fasting acid exposure of $11.7 \%$

Fig. 3 The receiver operating characteristic curves. (a) The reflux score, (b) supine acid exposure, and (c) supine reflux event percentage 
a Minimal reflux pattern
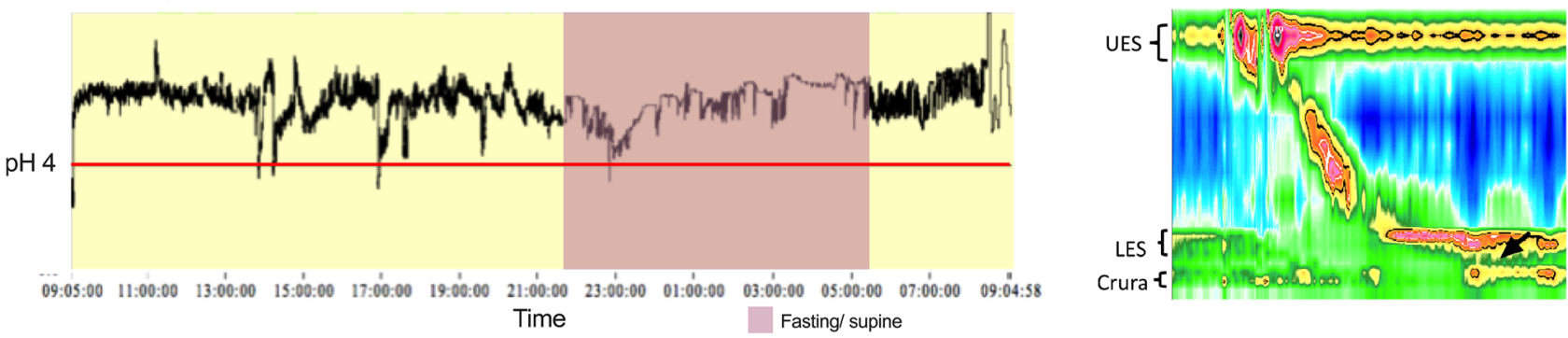

b Irritant reflux pattern
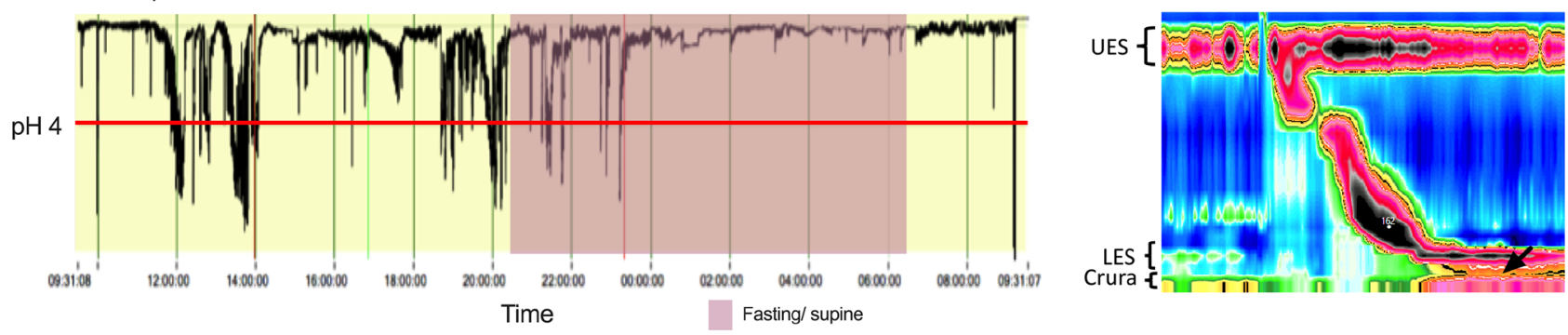

C Volume reflux pattern
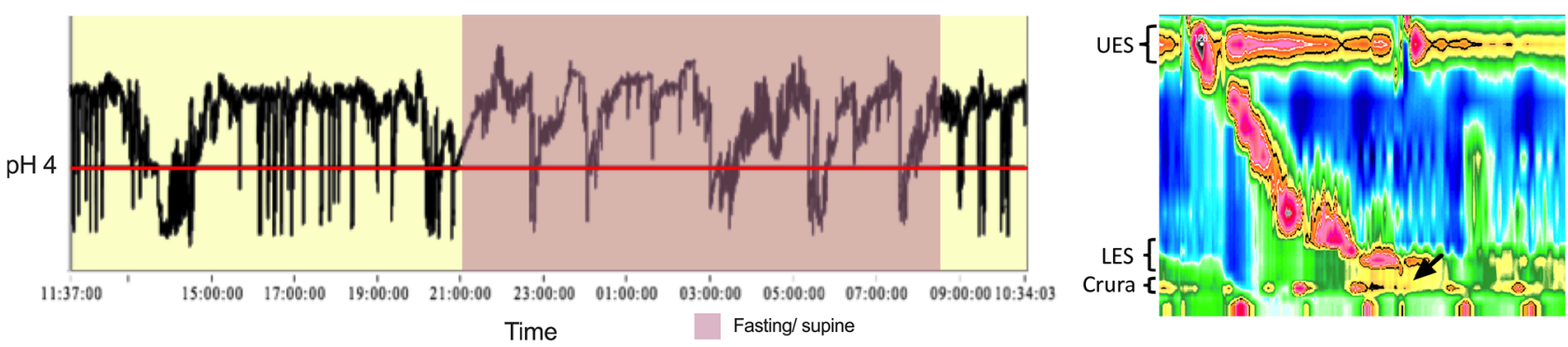

Fig. 4 Patterns of reflux in patients with hiatus hernia (24-h ambulatory pH and manometry). (a) Minimal reflux. (b) Irritant reflux. (c) Volume reflux (black arrows representing pockets of high pressure in the hiatus hernia)

Significant esophageal acid exposure can be present postSG in the absence of significant symptoms. The mean esophageal acid exposure in asymptomatic patients was high (median $4.2 \%$ ) compared to normal laboratory values [24]. Despite the significant elevation in acid exposure in symptomatic patients, it overlapped substantially with acid exposure for asymptomatic patients.

Supine acid exposure is a significant discriminant factor, and exposure of more than $2.65 \%$ should be considered diagnostic of GERD post-SG. This threshold was found to have $84 \%$ sensitivity and $68 \%$ specificity. Meeting this criterion should be considered a marker of substantially disrupted physiology given that minimal, if any, nocturnal esophageal acid exposure would be expected normally.

The patient-reported reflux questionnaire developed by Anvari et al. was initially developed and validated for patients undergoing Nissen fundoplication. The scoring system has been used to describe the SG population since then [14, 25]; however, a definition of abnormal GERD in this population had not been established. An objective reflux score threshold of 11.5 defined symptomatic reflux, with reasonable sensitivity of $84 \%$ and specificity of $68.4 \%$.
Notably, manometric variables, including LES basal tone and relaxation, did not discriminate between the two cohorts. This result appears to contradict previous studies by Braghetto et al. who found decreased LES resting pressure in symptomatic post-SG patients at 5 years [26] and 8-10 years [9].

Hiatus hernias (no more than $5 \mathrm{~cm}$ ) post-SG were also not found to be a significant discriminant factor of symptomatic reflux but were associated with higher acid exposure. Previous studies have implicated hiatus hernias as a significant factor in symptomatic GERD following SG, and consequently that reflux improves with hiatus hernia repair $[10,27]$. While these findings require objective validation, our data adds considerably to current literature. We would suggest that the presence of objectively quantified GERD based on physiological testing and coexistence of a hiatus hernia would more strongly predict a therapeutic response. Conversely, a patient presenting with symptoms in the absence of objective GERD may not benefit from intervention.

The limitations of this study include the single-center nature of the study, which limits the sample size to an extent. On the other hand, we felt this aspect provided streamlined decision-making and management in terms of patient 
Table 4 Univariate binary logistic regressions of factors associated with the presence of hiatus hernia post-sleeve gastrectomy

\begin{tabular}{|c|c|c|c|}
\hline \multirow[t]{2}{*}{ Variable } & \multicolumn{3}{|c|}{ Univariate regression } \\
\hline & Odds ratio & $95 \%$ confidence interval & $p$ value \\
\hline Symptomatic reflux & 1.250 & $0.583-2.680$ & 0.566 \\
\hline Age & 1.031 & $0.999-1.065$ & 0.061 \\
\hline Gender & 1.882 & $0.629-5.626$ & 0.258 \\
\hline Pre-operative weight & 0.997 & $0.982-1.012$ & 0.703 \\
\hline Pre-operative BMI & 1.010 & $0.962-1.060$ & 0.683 \\
\hline Excess weight loss & 0.997 & $0.983-1.012$ & 0.710 \\
\hline Revisional sleeve gastrectomy & 0.983 & $0.390-2.479$ & 0.983 \\
\hline Reflux score & 1.011 & $0.987-1.035$ & 0.370 \\
\hline Dysphagia score & 1.033 & $0.973-1.033$ & 0.286 \\
\hline Duration of follow-up & 0.995 & $0.976-1.014$ & 0.590 \\
\hline LES relaxation \% & 0.984 & $0.971-0.998$ & 0.022 \\
\hline LES basal tone & 0.980 & $0.951-1.011$ & 0.199 \\
\hline Hiatus hernia & 1.250 & $0.583-2.680$ & 0.566 \\
\hline Impaired esophageal peristalsis & 2.061 & $0.897-4.731$ & 0.088 \\
\hline Total acid exposure & 1.064 & $1.005-1.126$ & 0.034 \\
\hline Duration of each acid events & 0.998 & $0.799-1.247$ & 0.986 \\
\hline Number of acid events & 1.006 & $1.000-1.012$ & 0.046 \\
\hline Erect acid exposure & 1.029 & $0.964-1.098$ & 0.392 \\
\hline Supine acid exposure & 1.043 & $1.007-1.081$ & 0.018 \\
\hline Supine reflux event percentage & 1.014 & $0.997-1.031$ & 0.0 .96 \\
\hline Minimal reflux pattern & 0.301 & $0.119-0.764$ & 0.012 \\
\hline Irritant reflux pattern & 1.204 & $0.514-2.822$ & 0.669 \\
\hline Volume reflux pattern & 2.132 & $1.010-4.499$ & 0.047 \\
\hline
\end{tabular}

Italics refers to statistically significant variables selection for SG and pre-operative and post-operative care. Secondly, the absence of data on pre-operative gastroscopy and GERD precludes the evaluation of correlation between pre-operative and post-operative GERD, which is outside the scope of this study. We also did not evaluate potential postoperative confounding factors of reflux such as alcohol use and cigarette smoking.

Our future endeavors will focus on validating the findings in a separate SG cohort, including multicenter evaluation, which is required before widespread acceptance and generalization can occur. We will also investigate other aspects of symptomatic reflux post-SG including the influence of esophageal sensation, visceral hypersensitivity, and duodenogastric reflux. These criteria should also be assessed to determine their role in predicting response to treatment of GERD post-SG or need for further intervention and re-operation. Ultimately, this pursuit will be of considerable value to better understand the mechanisms of esophageal transit and pathophysiology of reflux following SG.

We have proposed threshold values for diagnosing abnormal reflux using both an objective questionnaire and 24-h pH monitoring. Moderately elevated acid exposure appears inherent to the procedure; however, significant elevation of supine acid exposure was the key pathological feature. We propose the use of an objective questionnaire and ambulatory $\mathrm{pH}$ when confronted with post-SG patients with reflux symptoms, especially when deciding whether this warrants further intervention and surgical management for GERD. Hopefully, this will assist substantially in the management and decision-making in reflux following SG.

\section{Compliance with Ethical Standards}

Conflict of Interest Professor Wendy Brown has received grants from Johnson and Johnson, grants from Medtronic, grants from GORE, personal fees from GORE, grants from Applied Medical, grants from Apollo Endosurgery, grants and personal fees from Novo Nordisk, and personal fees from Merck Sharpe and Dohme, all of which are outside the submitted work.

The remaining authors declare that they have no conflict of interest.

Ethical Approval Ethics approval was obtained from the Alfred Human Research and Ethics Committee (HREC) no. 380/16 and the Avenue Hospital HREC no. 236.

All procedures performed in studies involving human participants were in accordance with the ethical standards of the institutional and/or national research committee and with the 1964 Helsinki declaration and its later amendments or comparable ethical standards. 
Informed Consent Informed consent was obtained from all individual participants included in the study.

Open Access This article is licensed under a Creative Commons Attribution 4.0 International License, which permits use, sharing, adaptation, distribution and reproduction in any medium or format, as long as you give appropriate credit to the original author(s) and the source, provide a link to the Creative Commons licence, and indicate if changes were made. The images or other third party material in this article are included in the article's Creative Commons licence, unless indicated otherwise in a credit line to the material. If material is not included in the article's Creative Commons licence and your intended use is not permitted by statutory regulation or exceeds the permitted use, you will need to obtain permission directly from the copyright holder. To view a copy of this licence, visit http://creativecommons.org/licenses/by/4.0/.

\section{References}

1. Felsenreich DM, Prager G, Kefurt R, et al. Quality of life 10 years after sleeve gastrectomy: a multicenter study. Obes Facts. 2019;12(2):157. 66

2. Mandeville Y, Van Looveren R, Vancoillie PJ, et al. Moderating the enthusiasm of sleeve gastrectomy: up to fifty percent of reflux symptoms after ten years in a consecutive series of one hundred laparoscopic sleeve gastrectomies. Obes Surg. 2017;27(7):1797-803.

3. Genco A, Soricelli E, Casella G, et al. Gastroesophageal reflux disease and Barrett's esophagus after laparoscopic sleeve gastrectomy: a possible, underestimated long-term complication. Surg Obes Relat Dis. 2017;13(4):568-74.

4. Iannelli A, Treacy P, Sebastianelli L, et al. Perioperative complications of sleeve gastrectomy: review of the literature. J Minim Access Surg. 2019;15(1):1-7.

5. Chiu S, Birch DW, Shi X, et al. Effect of sleeve gastrectomy on gastroesophageal reflux disease: a systematic review. Surg Obes Relat Dis. 2011;7(4):510-5.

6. Oor JE, Roks DJ, Ünlü Ç, et al. Laparoscopic sleeve gastrectomy and gastroesophageal reflux disease- a systematic review and metaanalysis. Am J Surg. 2016;211:250-67.

7. Yeung KTD, Penney N, Ashrafian L, et al. Does sleeve gastrectomy expose the distal esophagus to severe reflux?: a systematic review and meta-analysis. Ann Surg. 2020;271(2):257-65.

8. Biter LU, van Buuren MMA, Mannaerts GHH, et al. Quality of life 1 year after laparoscopic sleeve gastrectomy versus laparoscopic Roux-en-Y gastric bypass: a randomized controlled trial focusing on gastroesophageal reflux disease. Obes Surg. 2017;27(10):255765 .

9. Braghetto I, Korn O. Late esophagogastric anatomic and functional changes after sleeve gastrectomy and its clinical consequences with regards to gastroesophageal reflux disease. Dis Esophagus. 2019;32(6):doz020. https://doi.org/10.1093/dote/doz020

10. Mahawar KK, Carr WR, Jennings N, et al. Simultaneous sleeve gastrectomy and hiatus hernia repair: a systematic review. Obes Surg. 2015;25(1):159-66.
11. Yehoshua RT, Eidelman LA, Stein M, et al. Laparoscopic sleeve gastrectomy-volume and pressure assessment. Obes Surg. 2008;18(9):1083-8.

12. Vargas EJ, Bazerbachi F, Calderon G, et al. Changes in time of gastric emptying after surgical and endoscopic bariatrics and weight loss: a systematic review and meta-analysis. Clin Gastroenterol Hepatol. 2020;18(1):57-68. e5

13. Burgerhart JS, Schotborgh CA, Schoon EJ. Effect of sleeve gastrectomy on gastroesophageal reflux. Obes Surg. 2014;24:1436 41.

14. Gorodner V, Buxhoeveden R, Clemente G, et al. Does laparoscopic sleeve gastrectomy have any influence on gastroesophageal reflux disease? Preliminary results. Surg Endosc. 2015;29(7):1760-8.

15. Rebecchi F, Allaix ME, Giaccone C. Gastroesophageal reflux disease and laparoscopic sleeve gastrectomy: a physiopathological evaluation. Ann Surg. 2014;260:909-15.

16. Johari Y, Ooi G, Burton P, et al. Long-term matched comparison of adjustable gastric banding versus sleeve gastrectomy: weight loss, quality of life, hospital resource use and patient-reported outcome measures. Obes Surg. 2020;30(1):214-23.

17. Visick AH. A study of the failures after gastrectomy. Ann R Coll Surg Engl. 1984;3(5):266-84.

18. Anvari M, Allen C, Born A. Laparoscopic Nissen fundoplication is a satisfactory alternative to long-term omeprazole therapy. Br J Surg. 1995;82(7):938-42.

19. Dakkak M, Bennett JR. A new dysphagia score with objective validation. J Clin Gastroenterol. 1992;14(2):354-8.

20. Burton PR, Brown WA, Laurie C, et al. The effect of laparoscopic adjustable gastric bands on esophageal motility and the gastroesophageal junction; analysis using high resolution video manometry. Obes Surg. 2009;19(7):905-14.

21. Kahrilas PJ, Ghosh SK, Pandolfino JE. Esophageal motility disorders in terms of pressure topography: the Chicago classification. J Clin Gastroenterol. 2008;42:627-35.

22. Hosmer Jr DW, Lemeshow S, Sturdivant RX. Applied logistic regression. 3rd ed. Hoboken: Wiley; 2013.

23. Guilherme MR, Peters JH, DeMeester TR, et al. Multivariate analysis of factors predicting outcome after laparoscopic Nissen fundoplication. J Gastrointest Surg. 1999;3:292-300.

24. Chen RY, Burton PR, Ooi GJ, et al. The physiology and pathophysiology of gastroesophageal reflux in patients with laparoscopic adjustable gastric band. Obes Surg. 2017;27(9):2434-43.

25. Desart K, Rossidis G, Michel M, et al. Gastroesophageal reflux management with the LINX(R) system for gastroesophageal reflux disease following laparoscopic sleeve gastrectomy. J Gastrointest Surg. 2015;19(10):1782-6.

26. Braghetto I, Csendes A, Lanzarini E, et al. Is laparoscopic sleeve gastrectomy an acceptable primary bariatric procedure in obese patients? Early and 5-year postoperative results. Surg Laparosc Endosc Percutan Tech. 2012;22:479-86.

27. Soricelli E, Iossa A, Casella G, et al. Sleeve gastrectomy and crural repair in obese patients with gastroesophageal reflux disease and/or hiatal hernia. Surg Obes Relat Dis. 2013;9(3):356-61.

Publisher's Note Springer Nature remains neutral with regard to jurisdictional claims in published maps and institutional affiliations. 